\title{
NHÂ̂N XÉT TÌNH HÌNH PHẪU THUÂTT U BUỒNG TRỨNG Ở PHỤ NỮ MÃN KINH TẠI BỆNH VIỆN PHỤ SẢN HÀNộI
}

\begin{abstract}
TÓM TẮT.
Nghiên cứu nhằm mục tiêu mô tả đăc điểm lâm sàng và cận lâm của các bệnh nhân u buồng trứng được phấu thuật tại Bệnh viện Phụ sản Hà Nội từ tháng $1 / 2019$ đển tháng 12/2020 và nhận xét kết quả phẫu thuật của nhóm bệnh nhân trên. Chúng tôi tiến hành nghiên cứu mô tả cắt ngang trên 131 bệnh nhân u buồng trứng được phẫu thuật tại Bệnh viện Phụ sản Hà Nôi. Kết quả nghiên cứu cho thẩy: Tỷ lệ UBT ác tính là 21,4\%, Tuổi TB của đối tượng nghiên cứu là $57,5 \pm 7,7$ tuổi. Tuổi TB của nhóm BN có UBT ác tính là $61,7 \pm 3,5$ cao hơn tuổi TB của nhóm BN có UBT lành tính là $53,1 \pm 4,1$. Trong nhóm UBT lành tính, typ thanh dịch chiếm nhiều nhất (45,9\%). Trong nhóm u ác tính, typ ung thư biểu mô chế nhây chiếm nhiều nhất. đa số BN có UBT lành tính thức hiên phương pháp phẫu thuật nội soi $(90,3 \%)$, đa số BN có UBT ác tính thực hiên phướng pháp mổ mở (92,9\%). Phần lớn BN có UBT lành tính thực hiện cắt phần phu 2 bên $(95,1 \%)$, và $100 \%$ BN có UBT ác tính được phẫu thuâtt triệt đề.
\end{abstract}

Tư khóa: u buồng trứng, ung thư buồng trứng, phẫu thuật.

\section{SUMMARY \\ REVIEW OF SURGICAL STATUS OF OVARIAN TUMOR IN POSTMENOPAUSAL WOMEN AT HANOI OBSTETRICS AND GYNECOLOGY HOSPITAL}

The purpose of this study was to describe the clinical and laboratory characteristics of ovarian tumor patients who were operated on at Hanoi Obstetrics and Gynecology Hospital from January 2019 to December 2020. We conducted a cross-sectional descriptive study on 131 ovarian tumor patients who were operated on at Hanoi Obstetrics and Gynecology Hospital. The study results showed that: The rate of ovarian cancer is $21.4 \%$, The average age of the study subjects is $57.5 \pm 7.7$ years old. The mean age of the group of patients with ovarian cancer was $61.7 \pm 3.5$, higher than the average age of the group of patients with benign ovarian tumor of $53.1 \pm 4.1$. In the group of benign ovarian tumors, the serous type accounts for the most $(45.9 \%)$. In the cancer group, the mucinous carcinoma type accounts for the most. the majority of patients with benign tumors performed laparoscopic surgery $(90.3 \%)$, the majority of patients with ovarian cancer performed open surgery $(92.9 \%)$. The majority

${ }^{1}$ Trường Đại học Y Hà Nội

Chiu trách nhiệm chính: Trân Văn Dũng

Email: dungtran.bvtn@gmail.com

Ngày nhận bài: 13.9.2021

Ngày phản biện khoa học: 27.10.2021

Ngày duyệt bài: 15.11.2021
Trần Văn Dũng ${ }^{1}$, Lê Thị Anh Đào ${ }^{1}$

of patients with benign tumors underwent bilateral adnexectomy $(95.1 \%)$, and $100 \%$ of patients with ovarian cancer underwent radical surgery.

Keywords: ovarian tumor, ovarian cancer, surgery.

\section{I. ĐẶT VẤN ĐỀ}

U buồng trứng (UBT) là một trong những khối u của hê sinh dục nữ. Bênh có thể găp ở mọi lứa tuổi, từ trẻ em gái chưa dây thì đênn những người đã mãn kinh. Phân lớn các khối u buồng trứng ở phụ nữ độ tuổi sinh đẻ là các khối u lành tính, trái lại ở phụ nữ mãn kinh xu hướng ác tính thường găp hơn¹.

Về mặt lý thuyết, khi phụ nữ mãn kinh, buông trứng ngừng hoạt động, không còn hiện tượng các nang noãn phát triển và phóng noãn nên khả năng tổn thương của buồng trứng giảm xuống. Tuy nhiên, trong thực tế đây là lứa tuổi hay gặp ung thư buồng trứng (UTBT) nhất, $50 \%$ số ca mắc UTBT găp ở phu nữ trên 65 tuổi ${ }^{1}$. Tai Viêt Nam, theo thống kê của GLOBOCAN 2020 có khoảng 1400 trường hợp mắc mới và khoảng 923 ca tử vong do ung thư buông trứng².

Bênh viên Phư sản Hà Nội là cơ sở sản phụ khoa đâu ngành của thành phố Hà Nội, hàng năm bệnh viện điêuu trị cho hàng trăm ca u buông trứng. Với mong muốn nghiên cứu về triệu chứng lâm sàng, cận lâm sàng của các trường hợp u buông trứng ở bệnh nhân mãn kinh và kết quả mô bệnh học sau phẫu thuật từ đó có thể rút ra một số đặc điểm với hy vọng dự báo tương đối chính xác tính chất lành hay ác tính của một khối u buồng trứng, vì vậy chúng tôi tiến hành nghiên cứu đề tài: "Nhận xét tình hình phẫu thuật u buông trứng ở phụ nữ mãn kinh tại bệnh viện Phu sản Hà Nội " mục tiêu: Mô tả đăc điểm lẩm sàng, cân lâm sàng của phu nữ mã் kinh có u buông trứng được phẫu thuật tại Bệnh viện Phụ sản Hà Nội tư tháng 1/2019 đên 12/2020 và nhânn xét kết quả phẫu thuật u buồng trưng ở những trường hợp trên.

\section{II. ĐỐI TƯỢNG VÀ PHƯƠNG PHÁP NGHIÊN CỨU}

1. Đối tượng: Bệnh nhân được chẩn đoán xác định là u buồng trứng ở phụ nữ mãn kinh và được điều tri phẫu thuât tai Bệnh viện Phu sản Hà Nội từ $1 / 1 / 2019$ đến $31 / 12 / 2020$, có đủ các tiêu chuẩn chọn mẫu nghiên cứu.

\section{Phương pháp nghiên cứu}

Thiết kế nghiên cứu: Mô tả cắt ngang 
Thời gian nghiên cứu: Từ tháng 01/2019 đến tháng 12/2020.

Địa điểm nghiên cứu: Bv Phụ sản Hà Nội.

Phương pháp chọn mẫu và cỡ mẫu Cỡ mẫu Áp dụng công thức:

$$
\mathrm{n}=Z_{(1-\alpha / 2)}^{2} \frac{p(1-p)}{d^{2}}
$$

Trong đó: $\mathrm{n}$ là số bệnh nhân mãn kinh bị u buồng trứng.

$Z_{(1-\alpha / 2)}^{2}$ là hệ số giới hạn tin cậy, bằng 1,962; p: Tỷ lệ ung thư buồng trứng ở phụ nữ mãn kinh, $p=0,221$ theo tác giả Cao Thị Thuý Hà nghiên cứu tại BVPSTW năm 2016; d độ chính xác tuyệt đối mong muốn, lấy $\mathrm{d}=0,09$

Thay vào công thức trên ta có được $n=128$

Trong thời gian nghiên cứu có tất cả 131 bệnh nhân mãn kinh có chẩn đoán sau phẫu thuật là UBT trong khoảng thời gian từ 1/1/2019

\section{KẾT QUẢ NGHIÊN CỨU}

\section{1. Đặc điểm đối tượng nghiên cứu}

Bảng 3. 1. Phân bố bệnh nhân theo nhóm tuổi

\begin{tabular}{|c|c|c|c|c|c|c|c|}
\hline \multirow{2}{*}{ 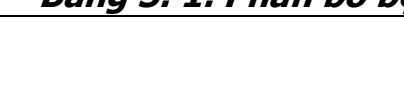 } & \multicolumn{2}{|c|}{$<55$} & \multicolumn{2}{|c|}{$55-64$} & \multicolumn{2}{|c|}{$\geq 65$} & \multirow{2}{*}{$\begin{array}{c}\text { Tuối trung } \\
\text { bình }\end{array}$} \\
\hline & $\mathbf{N}$ & $\%$ & $\mathbf{N}$ & $\%$ & $\mathbf{N}$ & $\%$ & \\
\hline UBT lành tính $(\mathrm{N} 1=103)$ & 12 & 9,2 & 61 & 46,5 & 30 & 22,9 & $53,1 \pm 4,1$ \\
\hline UBT ác tính (N2=28) & 3 & 2,3 & 9 & 6,9 & 16 & 12,2 & $61,7 \pm 3,5$ \\
\hline Tống số & 15 & 11,5 & 70 & 53,4 & 46 & 35,1 & $57,5 \pm 7,7$ \\
\hline $\mathbf{P}$ & \multicolumn{6}{|c|}{$>0,05$} & $>0,05$ \\
\hline
\end{tabular}

Nhận xét: - Tuổi TB của đối tượng nghiên cứu là $57,5 \pm 7,7$ tuổi. Tuổi TB của nhóm BN có UBT ác tính là $61,7 \pm 3,5$ cao hơn tuổi TB của nhóm BN có UBT lành tính là $53,1 \pm 4,1$

- Trong nghiên cứu, đa số BN có độ tuổi từ 55-64 tuổi chiếm 53,4\%. BN dưới 55 tuổi và từ 65 tuổi trở lên chiếm tỷ lệ thấp hơn là $11,5 \%$ và $35,1 \%$.

Bảng 3.2. Các triệu chứng thực thể của UBT khi thăm khám

\begin{tabular}{|c|c|c|c|c|c|c|c|}
\hline & \multicolumn{3}{|c|}{ U lành tính (n=103) } & \multicolumn{3}{|c|}{ U ác tính $(n=28)$} \\
\hline & & $\mathbf{n}$ & $\%$ & $\mathbf{P}$ & $\mathbf{n}$ & $\%$ & $\mathbf{P}$ \\
\hline \multirow{2}{*}{ Vị trí } & Một bên & 90 & 87,4 & \multirow{2}{*}{$<0,05$} & 18 & 64,3 & \multirow{2}{*}{$>0,05$} \\
\hline & Hai bên & 13 & 12,6 & & 10 & 35,7 & \\
\hline \multirow{2}{*}{ Mật độ u } & Chắc & 38 & 36,9 & \multirow{2}{*}{$<0,05$} & 12 & 42,9 & \multirow{2}{*}{$>0,05$} \\
\hline & Mềm & 65 & 63,1 & & 16 & 57,1 & \\
\hline \multirow{2}{*}{$\begin{array}{c}\text { Tính chất di } \\
\text { động }\end{array}$} & Di động & 73 & 70,9 & \multirow{2}{*}{$<0,05$} & 4 & 14,3 & \multirow{2}{*}{$<0,05$} \\
\hline & Hạn chế di động & 30 & 29,1 & & 24 & 85,7 & \\
\hline
\end{tabular}

Nhận xét: Trong nhóm bệnh nhân UBT lành tính cho thấy:

- U một bên nhiều hơn u hai bên $(87,4 \%$ và $12,6 \%)$, sự khác biệt có ý nghĩa với $p<0,005$.

- Các UBT lành tính mật độ mềm nhiều hơn so UBT mật độ chắc $(63,1 \%$ và $36,9 \%)$, sự khác biệt có ý nghĩa thống kê với $\mathrm{P}<0,05$

$\mathrm{U}$ di động chiếm 70,9\% nhiêu hơn u hạn chế di động $(29,1 \%)$, sự khác biệt có ý nghĩa thống kê với $P<0,05$. đến 31/12/2020 tại Bệnh viện Phụ sản Hà Nội có đú các tiêu chuẩn chọn mẫu nghiển cứu $=>$ chọn

$n=131$.

Công cụ thu thập số liệu: Xây dựng mẫu bệnh án nghiên cứu phù hợp với mục tiêu nghiên cứu. Số liều thu được từ những bênh án đủ tiêu chuẩn tại kho hồ sơ bệnh án của phòng Kế hoạch Tổng hợp của Bệnh viện Phụ sản Hà Nội.

3. Xử lý số liệu: Số liệu sau khi thu thập sẽ 的 hiện bằng phần mềm SPSS 20.

4. Đạo đức nghiên cứu: Mọi thông tin cá nhân về đối tượng nghiên cứu được giữ kín. Các số liệu, thông tin thu thập được chỉ phục vụ cho mục đích nghiên cứu, không phục vụ cho mục đích nào khác.

\section{Bảng 3.3. Phân bố các typ MBH của UBT sau phẫu thuật}


VIETNAM MEDICAL JOURNAL N01 - DECEMBER - 2021

\begin{tabular}{|c|c|c|c|c|}
\hline Loại u & Typ u & Số lượng & Tỷ lệ \% & $\mathbf{p}$ \\
\hline \multirow{5}{*}{$\begin{array}{l}\text { U buônng trứng } \\
\text { lành tính } \\
(\mathbf{N}=103)\end{array}$} & Thanh dich & 43 & 41,7 & \multirow{5}{*}{$\mathrm{p}<0,05$} \\
\hline & U nhầy & 17 & 16,5 & \\
\hline & Dạng nội mạc & 5 & 4,9 & \\
\hline & U quái trưởng thành & 25 & 24,3 & \\
\hline & U sợi & 13 & 12,6 & \\
\hline \multirow{7}{*}{$\begin{array}{c}\text { U buông trứng } \\
\text { ác tính } \\
(\mathbf{N}=\mathbf{2 8})\end{array}$} & Ung thư biểu mô tuyến thanh dịch & 6 & 21,4 & \multirow{7}{*}{$p>0,05$} \\
\hline & Ung thư biểu mô dạng nội mạc & 5 & 17,9 & \\
\hline & Ung thư biếu mô chế nhây & 10 & 35,7 & \\
\hline & Ung thư biếu mô tế bào sáng & 3 & 10,6 & \\
\hline & U quái trưởng thành hóa ác & 1 & 3,6 & \\
\hline & U tế bào mâm & 1 & 3,6 & \\
\hline & U tế bào hạt & 2 & 7,2 & \\
\hline
\end{tabular}

Nhận xét: Trong nhóm UBT lành tính, u biểu mô thanh dịch chiếm nhiều nhất (41,7\%), u dạng nội mạc chiếm ít nhất $(7,8 \%$ và $4,9 \%)$. Có sự khác biệt giữa typ dạng nội mạc với các typ u còn lai với $\mathrm{p}<0,05$.

Trong nhóm u ác tính, ung thư biểu mô chế

nhầy chiếm tỷ lệ cao nhất với $35,7 \%$, U quái trưởng thành hóa ác và u tế bào mầm chiếm tỷ lệ thấp nhất $(3,6 \%)$.

Sự khác biệt không có ý nghĩa thống kê với $p>0,05$.

\section{3. Đặc điểm chẩn đoán hình ảnh của UBT}

Bảng 3.4. Phương pháp phẫu thuật

\begin{tabular}{|c|c|c|c|c|c|c|c|}
\hline \multirow[t]{2}{*}{ (a) } & \multicolumn{2}{|c|}{ Tổng số } & \multicolumn{2}{|c|}{ UBT lành tính } & \multicolumn{2}{|c|}{ UBT ác tính } & \multirow[b]{2}{*}{$\mathbf{p}$} \\
\hline & $\mathbf{n}$ & $\%$ & $\mathbf{n}$ & $\%$ & $\mathbf{n}$ & $\%$ & \\
\hline Phâ̂u thuật nội soi & 95 & 72,5 & 93 & 90,3 & 2 & 7,1 & \\
\hline Phâu thuật nội soi chuyến mố mở & 2 & 1,5 & 2 & 1,9 & 0 & 0 & \\
\hline Phâu thuật mố mở & 34 & 25,9 & 8 & 7,8 & 26 & 92,9 & p $<0,03$ \\
\hline Tống & 131 & 100 & 103 & 100 & 28 & 100 & \\
\hline
\end{tabular}

Nhận xét: Trong nghiên cứu, đa số BN có UBT lành tính thực hiện phương pháp phẫu thuật nôi soi $(90,3 \%)$, đa số BN có UBT ác tính thực hiện phương pháp mổ mở (92,9\%). Có 2 trường hợp UBT lành tính phẫu thuât nội soi chuyển mổ mở do u dính tiểu khung nhiều.

Có sự khác biệt về phương pháp phẫu thuật của nhóm $B N$ có UBT lành tính và ác tính có ý nghĩa thống kê $(p<0,05)$.

3.4. Phương pháp xử trí khi phẫu thuật

Bảng 3.5. Phương pháp xử trí khi phẫu thuật

\begin{tabular}{|c|c|c|c|c|}
\hline \multirow{2}{*}{$\begin{array}{c}\text { Phương pháp } \\
\text { xữ trí }\end{array}$} & \multicolumn{3}{|c|}{$\begin{array}{c}\text { UBT lành tính } \\
\mathbf{n = 1 0 3}\end{array}$} & $\begin{array}{c}\text { UBT ác tính } \\
\mathbf{n = 2 8}\end{array}$ \\
\cline { 2 - 5 } & $\mathbf{n}$ & $\mathbf{\%}$ & $\mathbf{n}$ & $\mathbf{\%}$ \\
\hline Cắt 2 phần phụ & 98 & 95,1 & 0 & 0 \\
\hline $\begin{array}{c}\text { Cắt tứ cung + } \\
\text { 2 phần phụ }\end{array}$ & 5 & 4,9 & 0 & 0 \\
\hline Phẩu thuật triệt để & 0 & 0 & 28 & 100 \\
\hline
\end{tabular}

Nhân xét: Trong nghiên cứu, đa số BN có UBT lành tính thực hiện cắt phần phụ 2 bên $(95,1 \%)$, và $100 \%$ BN có UBT ác tính được phẫu thuật triệt để.

- Có 5/103 trường hợp UBT lành tính cắt tử cung và 2 phần phụ do UBT kèm theo các bệnh lý tử cung: 3 trường hợp $\mathrm{U}$ xơ tử cung to, 1

trường hợp loạn sản niêm mạc TC gây chảy máu, 1 trường hợp ung thư niêm mạc TC.

\section{BÀN LUẬN}

Trong nghiên cứu của chúng tôi, với 131 trường hợp u buồng trứng, về tổng thể cho thây u buồng trứng lành tính chiếm $78,6 \%$, u buồng trứng ác tính chiếm $21,4 \%$. Tỷ lệ UBT ác tính trong nghiên cứu của chúng tôi tướng tự kết quả của tác giả Cao Thị Thúy Hà $(22,1 \%)^{3}$ và tác giả Vũ Thị Kim Chi và cộng sự là $19 \% 4$.

Theo nghiên cứu của Nguyễn Thị Ngọc Phượng trên 2421 bệnh nhân, tỷ lệ UBT lành tính là $93,6 \%$ và UBT ác tính là $6,4 \%{ }^{5}$ thì tỷ lệ UBT ác tính của chúng tôi cao hơn nhiều. Sở dĩ nghiên cứu của chúng tôi cao hơn nhiều do chúng tôi chỉ nghiên cứu trên lứa tuổi mãn kinh. Các đối tượng trong nghiên cứu được chia thành nhiêu nhóm tuổi. Bệnh nhân nhiều tuổi nhất là 83 tuổi, bệnh nhân có tiền sử mổ bóc u nang buồng trứng cách đây 30 năm, lần này vào viện khám do thấy đau tức hạ vị, bụng to, tự sờ thấy khối u hố chậu trái. Bệnh nhân vào viện được chẩn đoán là UBT dạng thanh dịch lành tính bền trái, kích thước $9,5 \mathrm{~cm}$. Theo nghiên cứu của tác giả Cao Thị Thúy Hà, bênh nhân nhiều tuổi nhất là 85 tuổi ${ }^{3}$. tuổi bệnh nhân bị mắc UBT theo kết quả của chúng tôi là phù hợp với kết quả của các tác giả khác xu 
hướng mắc UBT ác tính tăng lên ở phụ nữ mãn kinh. Trong nghiên cứu này, các u di động chiếm đa số. Riêng nhóm u lành tính, các u di động chiếm $70,9 \%$ còn trong nhóm u ác tính, tỷ lệ u hạn chế di động lên đến $85,7 \%$. Các kết quả nghiên cứu của chúng tôi cũng tương tự một số nghiên cứu khác. Chúng tôi cho rằng tỷ lệ u ác tính không di động chiếm số lượng lớn là bởi các u này hầu hết phát hiện ở giai đoạn muộn. Khi ở giai đoạn muộn, ngoài kích thước khối u đã lớn gây hạn chế di động còn do các tế bào u xâm lấn ra vỏ ngoài hoặc thậm chí xâm lấn các tổ chức xung quanh vì vậy theo cơ chế sinh u thì mô u phát triển đến đâu, chúng tăng sinh mạch và mô liên kết đến đó đồng thời cũng tạo ra phản ứng bảo vệ của cơ thể biểu hiện bằng hình ảnh xâm nhập viêm (các tế bào một nhân), tăng sinh xơ để ngăn chặn, hạn chế sự phát triển và lan tràn của mô u. Chính những yếu tố trên đã làm cho mô u mất tính chất di động. Một số nghiên cứu ở nước ngoài cho biết có tới $80 \%$ các trường hợp ung thư buồng trứng khi được chẩn đoán đã có sự lan tràn mô u ngoài buồng trứng ${ }^{6}$. Theo Vũ Bá Quyết, đa số bệnh nhân có khối u dính, chiếm tỷ lệ $68,5 \%$ và tỳ lệ bệnh nhân có khối u di động chiếm $31,5 \%$. Trong nghiên cứu của chúng tôi, có $63,1 \%$ các UBT lành tính có mật độ mềm và $57,1 \%$ UBT ác tính có mật độ mềm. Theo chúng tôi, tỷ lệ này là hợp lý vì số bệnh nhân u nang thanh dịch buồng trứng chiếm 33,9\% và u nang nhầy chiếm $16,5 \%$.

*Kết quả phẫu thuật. Có sự khác biệt về phương pháp phẫu thuật của nhóm BN có UBT lành tính và ác tính có ý nghĩa thống kê $(p<0,05)$.

Có thể nói PTNS là bước ngoặt trong kỹ thuật điều trị UBT, một trong những bệnh thường gặp trong phu khoa, tỷ lệ PTMM và PTNS chuyển PTMM giảm nhiều mang lại nhiều lợi ích cho người bệnh. Năm 2008, theo một nghiển cứu của Nguyễn Bình $\mathrm{An}^{8}$ thì trong vòng 6 tháng đầu năm 2008 có 200 trường hợp u nang buồng trứng được PTNS tại bệnh viện PSTU. Các trường hợp UTBT được mổ mở để tiện quan sát phẫu trường và phẫu thuật triệt để

Qua đây chúng tôi nhận thây: PTNS được các nhà phụ khoa và người bệnh ngày một quan tâm nhiều hơn bởi tính ưu việt của nó: thời gian mổ ngắn, bệnh nhân hồi phục nhanh sau mổ. PTNS ngày càng được hoàn thiện về kỹ thuật và đó khẳng định lợi thế của mình so với PTMM, đặc biệt trong điều trị u nang buồng trứng lành tính. Có sự khác biệt về phương pháp phẫu thuật của nhóm $B N$ có UBT lành tính và ác tính có ý nghĩa thống kê $(p<0,05)$.

Với những trường hợp u lành tính mà đối tượng là những phụ nữ mãn kinh thì việc đưa ra phương pháp phẫu thuật cắt 2 phần phụ và tử cung là hoàn toàn hợp lý. Những trường hợp u buồng trứng ác tính có chỉ định cắt rộng rẩi là phù hợp nhằm tránh tái phát hoặc bỏ sót $u$. Với những trường hợp u lan rộng, việc điều trị bổ trợ bằng hóa/ xạ trị là cần thiết và đúng phác đồ điều trị. Nghiên cứu của Nguyễn Thị Hương Linh về các u buồng trứng giáp biên cho thây: trong 116 trường hợp u buồng trứng giáp biên, có 79 trường hợp được phẫu thuật bảo tồn khả năng sinh sản ngay khi phẫu thuật lần đầu tiên (chiếm $67,5 \%)$, tỷ lệ được phẫu thuật triệt để ngay chiếm $31,6 \%$.

\section{KẾT LUẬN}

Tùy vào tính chất lành tính hay ác tính của UBT để đưa ra các phương pháp phấu thuật thích hợp. Qua đây chúng tôi thấy rằng với việc đánh giá, chọn lọc bệnh nhân kỹ càng, thận trọng trong thao tác phẫu thuật quyết định cho thành công của phẫu thuật.

\section{TÀI LIÊU THAM KHẢO}

1. Khổi u buồng trứng lành tính - Phu khoa và Sản khoa. Cẩm nang MSD-Phiên bản dành cho chuyên gia.

2. GLOBOCAN (2020). Cancer incidence, mortality and prevanlence worldwide, Lyon, IARC Press.

3. Cao Thị Thúy Hà (2016). Nghiên cứu U buồng trứng ở phu nữ mãn kinh được phẩu thuật tại Bênh viện Phư sản Trung ương, Luận án thạc sĩ, Trưởng Đại học $Y$ hà Nội, Hà Nội.

4. Vứ Thị Kim Chi (2014). Nghiên cứu U buồng trứng ở phụ nữ được phẫu thuật tại Bệnh viện Phự sản Trung ương, Luận án thạc sĩi, Trường Đại học Y hà Nội, Hà Nội.

5. Nguyến Thị Ngọc Phượng, Hà Tố Nguyên, Nguyển Xuẩn Trang (2005). Giá trị dự đoán ung thư buồng trứng của siêu âm trắng đen. Hội nghị sản phụ khoa Việt-Pháp, 10-11.

6. Fleischer.AC (1996). Early detection ovarian with transvaginal colour Doppler ultrasonography. Am J of Obstetrics and Gynecology, 174 (1), 101-106.

7. Vũ Bá Quyêt (2011). Nghiên cứu giá trị của CA 125 trong chẩn đoán giai đoạn và̀ theo dối đđiều trị bệnh ung thư biểu mô buồng trứng, Luận án Tiến sĩ $Y$ hoc, Trường Đại học $Y$ Hà Nội.

8. Nguyển Bình An (2008). Nhận xét về kết quả điêu trị u nang buồng trứng bắng phẫu thuật nội soi taii BVPSTU trong 6 tháng đâu năm 2008, Trường Đại học $Y$ Hà Nội.

9. Nguyến Thị Hương Linh (2011). Nghiên cứu đặc điểm lâm sàng, cận lâm sàng và xử trí u buồng trứng giáp biên tại Bệnh viên Phự sản Trung ương từ 2001 đến 2010, Luận văn BSCKII, Trường Đại học $Y$ Hà Nội. 